\title{
The effects of different recovery methods on anaerobic performance in combat sports athletes
}

\author{
Hakan Yarar ${ }^{1 凶}$, Ümit Gök ${ }^{1}$, Ahmet Dağtekin ${ }^{1}$, Yunus Saçan ${ }^{1}$, and Hüseyin Eroğlu \\ ${ }^{1}$ Faculty of Sport Sciences, Bolu Abant Izzet Baysal University, Bolu, Turkey; and ${ }^{2}$ School of Physical Education and Sport, \\ Kahramanmaraş Sütçü Imam University, Kahramanmaraş, Turkey
}

\section{Abstract}

Background: Athletes, who engage in combat sports, perform often several matches in a day during competitions. For this reason, recovery is a very important factor between matches. There are many different recovery methods applied by athletes and it is very important to know which one is more suitable for anaerobic performance. Objective: The aim of this study was to investigate the effects of different recovery methods on anaerobic performance in combat sports athletes. Methods: Thirteen experienced international level elite combat sports athletes (age $20.5 \pm 1.6$ years, body height $175.3 \pm 4.5 \mathrm{~cm}$, body mass $73.8 \pm 7.9 \mathrm{~kg}$, body fat $11.4 \pm 3.9 \%$, training experience $7.5 \pm 3.4$ years) have participated voluntarily in this study. Athletes were involved in passive recovery (PR), cold water immersion (CWI) and active recovery (AR) methods after countermovement jump and Wingate anaerobic test. Also, body temperature and rating of perceived exertion were evaluated. In this study, a randomized crossover design was used and applications lasted three days. All measurements were performed at three different times (baseline, $1^{\text {st }}$ and $2^{\text {nd }}$ session) in a day. Twoway analysis of variance with repeated measures was used for statistical analysis. Results: For the countermovement jump there was a significant increase after CWI and AR. A significant decrease was found in the Fatigue index after CWI recovery. Body temperature was increased after CWI, AR, and PR. Rating of perceived exertion has increased in AR. Moreover, there were no significant differences were found in peak power and mean power. Conclusions: The results indicate that during intermittent recovery, CWI positively impacted countermovement jump and fatigue index. Also, AR has positively affected countermovement jump performance, while negatively affected the rating of perceived exertion. Thus our findings suggest that $10 \mathrm{~min}$ of CWI and AR can be adopted in competitions when successive matches take place.

Keywords: anaerobic power, cold water immersion, active recovery, passive recovery

\section{Introduction}

Combat sports consist of many different Olympic and non-Olympic sports such as; wrestling, taekwondo, boxing, judo, karate, kickboxing, muay thai, etc. (Hammami et al., 2018). In these sports, national and international competition organizations follow a tournament schedule that requires athletes to have more than one match in a day. For this reason, the time is limited for the recovery between these matches (Monedero \& Donne, 2000). In combat sports, matches take place in a short time and at a high intensity. Therefore, a very important issue is the recovery between matches. Furthermore, many athletes ignore recovery strategies within their daily training or match programs (Calder, 2003). As a result, athletic performance might be reduced. Physical and physiological recovery between competitions is not only important for combat sports athletes but also for team sports athletes (Doeven et al., 2018; King \& Duffield, 2009). Ronglan et al. (2006) study have demonstrated that successive matches adversely affect team-sport athletes and reduce performance. Recovery is a crucial factor for the team and individual sports athletes, not only during competition between repeated performances but also in the training period (Calder, 2003). Intense training results in numerous physiological effects such as muscle damage, hyperthermia, dehydration, and glycogen depletion (Ihsan et al., 2016; Reilly \& Ekblom, 2005).

Recovery is defined as the return of the organism to its pre-exercise state (Hausswirth \& Le Meur, 2011). There are numbers of popular methods used by athletes to enhance recovery such as; stretching, massage, active recovery (AR), passive recovery (PR), cold water immersion (CWI), contrast water therapy, compression garments, hydrotherapy, and some nutritional practices (Halson, 2013; Mussi, 2018). In this study, AR, PR, and CWI applications, which are often used by athletes were compared. AR is defined as low-intensity (less than the anaerobic threshold and between $30 \%$ and $60 \%$ of the individual's maximal oxygen consumption) exercises applied after training and competition (Wiewelhove et al., 2018; Wilcock, 2005). During intense exercise, various waste metabolites (the lactic acid and hydrogen ions related to acidosis) accumulate

$\triangle$ Corresponding author: Hakan Yarar, e-mail hakanyarar96@hotmail.com, ORCID ${ }^{\circledR}$ record https://orcid.org/0000-0003-4652-5307

Article history: Received November 18 2020, Accepted July 25 2021, Published November 162021

Copyright: @ 2021 The Author(s). Published by Palacký University Olomouc. This is an open access article distributed under the terms of the Creative Commons Attribution License (https://creativecommons.org/licenses/by/4.0/), which permits unrestricted use, distribution, and reproduction in any medium, provided the original author and source are credited. This license does not cover any third-party material that may appear with permission in the article. 
within the muscle, inducing muscle fatigue and deterioration of performance (Lattier et al., 2004; Tokmakidis et al., 2011). AR reduces this waste metabolite and, with an associated increase in blood flow throughout the body, may increase the metabolism of waste substrates produced during exercise (Halson, 2013; Sharma et al., 2017; Tokmakidis et al., 2011; Wilcock, 2005). PR refers to inactivity post-exercise and the intrinsic return of the body to homeostasis (Sanders, 1996). CWI is a form of cold water therapy that improves the natural healing process of the human body. The possible benefit of CWI recovery is that due to the hydrostatic pressure and water temperature; reduce swelling, reduce muscle pain, reduce the feeling of fatigue, regulate localized blood flow, regulate localized tissue and internal temperature, regulate heart rate, reduce muscle spasms, reduce inflammation, and muscle damage (Ascensão et al., 2011; Belkadi et al., 2019; Dupuy et al., 2018; Higgins et al., 2017; Mooventhan \& Nivethitha, 2014; Wilcock, 2005).

In summary, the level of recovery is very important for sports performance between consecutive matches. The need to maximize recovery methods appears to be important to increase anaerobic performance. Therefore, the aim of this study was to assess the effect of different recovery methods on performance in countermovement jump (CMJ) and Wingate anaerobic test (WAnT).

\section{Methods}

\section{Participants}

Thirteen (wrestling, $n=3$; judo, $n=2$; wushu, $n=2$; boxing, $n=2$; karate, $n=2$; muay thai, $n=1$; kickboxing, $n=1)$, experienced elite international level combat sports athletes (age $20.5 \pm 1.6$ years, body height $175.3 \pm 4.5$ $\mathrm{cm}$, body mass $73.8 \pm 7.9 \mathrm{~kg}$, body fat $11.4 \pm 3.9 \%$, sport experience $7.5 \pm 3.4$ years) participated voluntarily in this study. The experiment was approved by the Clinical Research Ethical Committee of Abant Izzet Baysal University (decision no. 2019/230). Each participant signed informed consent.

\section{Experimental design}

The study was designed to simulate the tournament process of combat sports. Each subject was informed about the procedures (purpose, methods, contributions, and possible risks) before participating in the experiment. Two weeks before the experiment, the subjects were familiarized with the tests to avoid the learning effect during the testing period of the study. Subjects were asked to refrain from any physical activity during the experimental period. At the end of the familiarization, subjects were assigned to three groups. Three sessions of performance test (baseline, $1^{\text {st }}$ session, $2^{\text {nd }}$ session) were realized during each measurement day. After baseline and the $1^{\text {st }}$ session of performance test, 10-min specific recovery methods for each group were applied. In this study, randomized cross design was used where all groups applied the same recovery methods, but on different days. Between sessions 120 min resting was given. The schematic representation of the investigation is shown in Figure 1.

\section{Anthropometric and body composition measurements For the body height measurement to the nearest $0.1 \mathrm{~cm}$ via Stadiometer (Seca 700, Germany) was used. Body mass and body fat percentage were assessed by a bioelec- trical impedance analyzer (Tanita BC-418 MA, Tanita, Tokyo, Japan).}

Figure 1 Schematic representation of the investigation (for one day)
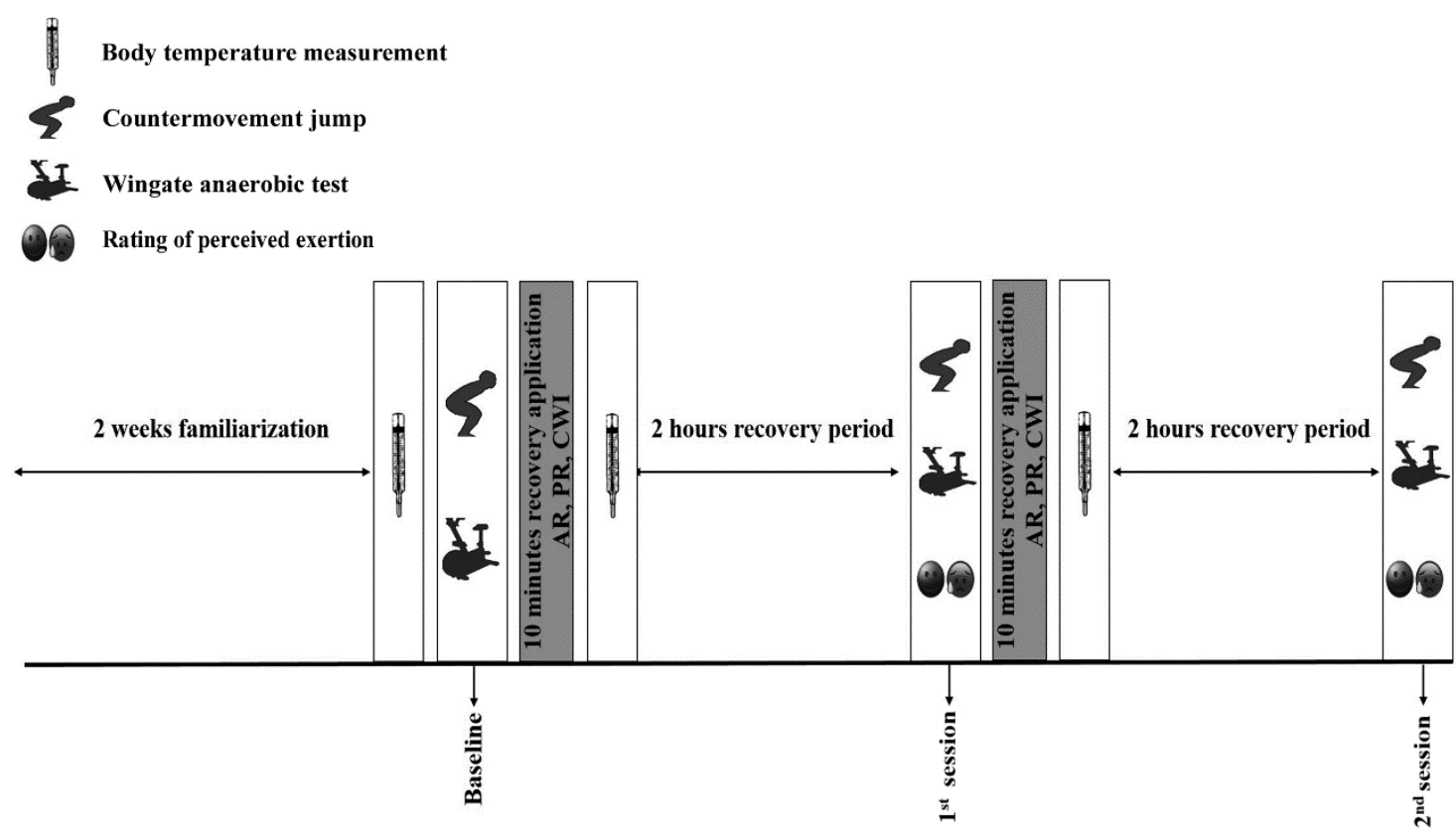

Note. $\mathrm{AR}=$ active recovery $; \mathrm{PR}=$ passive recovery $; \mathrm{CWI}=$ cold water immersion . 


\section{Cold water immersion protocol}

During the cold water immersion, subjects were submerged in a seated position to the waist level in cold water $\left(10-15^{\circ} \mathrm{C}\right)$. Cold water immersion was applied $10 \mathrm{~min}$ utes after the end of the performance tests. Water temperature was controlled before all measurements with a portable thermometer (Idden Welt) and the water temperature was maintained between $10-15{ }^{\circ} \mathrm{C}$ by adding ice. During the application, the subject wore shorts only.

\section{Active recovery protocol}

After all performance tests, 10-min active recovery was applied. The protocol consists of 5-min jogging and 5-min stretching exercise (quadriceps, hamstring, and calf muscles).

\section{Passive recovery protocol}

During passive recovery, the subjects rested in the supine position with the straight legs and arms positioned alongside the body. Passive recovery took 10 min after the performance application.

\section{CMJ}

In order to determine the vertical jump performance of the participants, the time they stayed in the air was measured using the Bosco Mat (Newtest 1000, Oulu, Finland). In this test, the athlete stood on the mat with weight evenly distributed over both feet. Hands were placed on the hips. The athlete squats down until the knees were bent at approximately $90^{\circ}$, the upper body kept straight. The athlete jumped vertically as high as possible and landed back on the mat with both feet hitting the ground at the same time. The best score of three attempts was recorded. Onemin resting was given between trials. The maximum flying time from experiments was recorded. Power calculated with the formula shown below (Sayers et al., 1999):

Peak power $(\mathrm{W})=\left[60.7^{*}\right.$ Jump height $\left.(\mathrm{cm})\right]$ $+[45.3 *$ Body mass $(\mathrm{kg})]-2055$.

\section{0 s WAnT}

The $30 \mathrm{~s}$ WAnT performance was conducted with a cycle ergometer (Monark Ergomedic 894E, Peak Bike, Sweden). Seat height was adjusted for each subject and toe clips were used to prevent the slipping of the feet from the pedals. Each participant cycled at 70-80 rpm after standard warm-up. At the beginning of the test, the subjects were instructed to pedal as fast as possible against unloaded resistance (Inbar et al., 1996). The resistance applied was adjusted relative to body weight $(0.075 *$ body weight in $\mathrm{kg})$. During the test when the subject reached $150 \mathrm{rpm} 30 \mathrm{~s}$, the measurement phase was started automatically. Verbal encouragement was given to each subject till the end of the test. In this test, peak power $(\mathrm{PP})$, mean power $(\mathrm{MP})$, minimum power, and their relative values were obtained from the software. The fatigue index (FI) was calculated by the formula of Inbar et al. (1996).

Fatigue index $=[$ peak power $(\mathrm{W})-\operatorname{minimum}$ power $(\mathrm{W})]$ / peak power $(\mathrm{W}) * 100$.
Body temperature measurement

Body temperature (BT) was measured using a portable ear thermometer (Braun ThermoScan, Braun, Kronberg, Germany).

\section{Rating of perceived exertion}

To assess the subject's efforts, during the application, athletes were asked to provide a rating of perceived exertion (RPE). The subjects completed a questionnaire (RPE scale) that probed their perception of physical fatigue. The scale consists of values ranging from 6-20 with 6 meaning easy and 20 meaning hard (Borg, 1970). After conducted the recovery application, the subjects were asked whether or not they felt that the application enhanced their recovery from the previous session and improved their subsequent physical performance.

\section{Statistical analysis}

All statistical tests were processed using SPSS software (Version 20.0; IBM, Armonk, NY, USA). To test normality, we used the Shapiro-Wilk test and Levene's test for the homogeneity of variance. Once the assumption of normality was confirmed, parametric tests were performed. Data of the Wingate test, CMJ, BT, and RPE were analyzed using a two-way (Recovery method $\times$ Time, $3 \times 3$ ) analysis of variance with repeated measures as the second factor. When appropriate, significant differences between means were determined using the Bonferroni test.

When a significant difference was found between times, one-way analysis of variance for repeated measures was used for the statistical analysis between consecutive measurements taken at baseline, $1^{\text {st }}$, and $2^{\text {nd }}$ session. When significant differences were found in application and time effect according to variance analysis, paired-samples $t$-test was used for assessing the differences between baseline and other times. Effect sizes were calculated for all variables using $\eta_{\mathrm{p}}^{2}$. The thresholds used for the interpretation of the effect size were: .01 small effect size, .06 medium effect size, .14 large effect size (Cohen, 1988). For the description of changes from baseline percent change $(\Delta \%)$ was calculated. The significance level was stated at $p \leq .05$.

\section{Results}

Results from the countermovement jump, peak power, mean power, and fatigue index values at baseline, after $1^{\text {st }}$ and $2^{\text {nd }}$ sessions, are presented in Table 1.

For the CMJ there was a time effect in CWI and AR, $\left.F(2,12)=5.390, p=.012, \eta_{\mathrm{p}}^{2}=.310\right)$. For the CWI highest value was seen after the $2^{\text {nd }}$ session $(\Delta \%+3.5)$. For AR, it was seen after the $1^{\text {st }}$ session $(\Delta \%+2.9)$.

For the FI there was also significant application and time effect, $F(4,24)=2.675, p=.043, \eta_{\mathrm{p}}^{2}=.182$; with the lowest value after the $1^{\text {st }}$ session $(\Delta \%-6.4)$ compared to values at baseline and after the $2^{\text {nd }}$ session in CWI recovery. There were no significant differences found in PP, $F(2,12)=3.217, p=.058, \eta_{\mathrm{p}}^{2}=.211$ and MP, $F(2$, 12) $=2.789, p=.081, \eta_{\mathrm{p}}^{2}=.189$. 
The changes in body temperature at baseline, and after the $1^{\text {st }}$ and $2^{\text {nd }}$ sessions are presented in Table 2 . There was a time effect, $F(2,12)=16.413, p<.001, \eta_{p}^{2}=.578$, in CWI, PR, and AR groups. The highest increase was found in the AR group $(\Delta \%:+1.4)$ during the $2^{\text {nd }}$ session.

Results from the RPE after the $1^{\text {st }}$ and $2^{\text {nd }}$ session recovery procedure are displayed in Table 3 . There was a time effect, $F(2,12)=6.257, p=.028, \eta_{\mathrm{p}}^{2}=0.343$, in AR groups. The highest increase was found in AR after the $2^{\text {nd }}$ session $(\Delta \%+10.5)$.

\section{Discussion}

The major findings of the present study were that values of CMJ were significantly higher after CWI and AR methods. The lowest FI score was seen in CWI as compared to AR and PR. It was seen that there was an increase in AR, PR, and CWI applications in BT values. It was determined that the highest BT value was in AR application. Moreover, the highest RPE scores were seen in AR applications.
In terms of CMJ, there was a significant increase in CWI and AR groups in the time effect. The changes were found in the AR baseline to the $1^{\text {st }}$ session $(2.9 \%)$ whereas in the CWI baseline to $2^{\text {nd }}$ session $(3.4 \%)$. The result was also confirmed by Rey et al. (2012), who reported that AR has improved CMJ performance. Also, Medina-Porqueres et al. (2016) presented a similar result as CWI exerts a beneficial effect on CMJ and vertical jump ability. Contrary to the study results stated above, Rowsell et al. (2009) and King and Duffield (2009) presented no significant difference in CMJ performance after CWI application. The reason for the different results obtained in these studies is thought to be due to the fact that the study group (female- junior) and study design were different. Due to the positive effects of $\mathrm{AR}$ and CWI on CMJ, it can be preferred for combat sports athletes between matches.

Further, our study showed no significant difference in PP values. Bielik (2010) found no significant difference in PP values after PR. Similarly, Ouergui et al. (2014) have studied kickboxing athletes and found that there was no

Table 1 Performance variables

\begin{tabular}{|c|c|c|c|}
\hline Variable & $\begin{array}{c}\text { Baseline } \\
M \pm S D\end{array}$ & $\begin{array}{l}\text { After } 1^{\text {st }} \text { session } \\
M \pm S D(\Delta \%)\end{array}$ & $\begin{array}{l}\text { After } 2^{\text {nd }} \text { session } \\
\quad M \pm S D(\Delta \%)\end{array}$ \\
\hline \multicolumn{4}{|c|}{ Countermovement jump (W) } \\
\hline Cold water immersion & $3494.3 \pm 458.7$ & $3554.5 \pm 532.4(+1.7)$ & $3615.8 \pm 487.2^{b}(+3.5)$ \\
\hline Passive recovery & $3526.2 \pm 463.2$ & $3582.5 \pm 492.8(+1.5)$ & $3578.5 \pm 501.3(+1.4)$ \\
\hline Active recovery & $3490.8 \pm 400.8$ & $3593.2 \pm 403.9^{b}(+2.9)$ & $3541.8 \pm 477.6(+1.4)$ \\
\hline \multicolumn{4}{|l|}{ Peak power (W/kg) } \\
\hline Cold water immersion & $12.6 \pm 1.4$ & $12.5 \pm 1.6(-0.8)$ & $13.1 \pm 1.3(+4.2)$ \\
\hline Passive recovery & $12.9 \pm 1.6$ & $12.9 \pm 1.7(-0.07)$ & $13.0 \pm 1.7(+0.4)$ \\
\hline Active recovery & $12.9 \pm 1.6$ & $13.1 \pm 1.5(+1.2)$ & $13.2 \pm 1.4(+2.0)$ \\
\hline \multicolumn{4}{|l|}{ Mean power (W/kg) } \\
\hline Cold water immersion & $8.6 \pm 0.5$ & $8.6 \pm 0.5(+0.2)$ & $8.7 \pm 0.5(+1.3)$ \\
\hline Passive recovery & $8.6 \pm 0.5$ & $8.7 \pm 0.5(+0.5)$ & $8.7 \pm 0.6(+1.5)$ \\
\hline Active recovery & $8.7 \pm 0.6$ & $8.8 \pm 0.5(+1.3)$ & $8.8 \pm 0.6(+1.8)$ \\
\hline \multicolumn{4}{|l|}{ Fatigue index (\%) } \\
\hline Cold water immersion & $60.7 \pm 10.1$ & $56.2 \pm 8.7^{\mathrm{a}}(-6.4)$ & $61.5 \pm 8.4(+2.4)$ \\
\hline Passive recovery & $63.6 \pm 12.3$ & $61.6 \pm 9.2(-3.1)$ & $59.8 \pm 10.2(-5.9)$ \\
\hline Active recovery & $59.8 \pm 8.7$ & $62.0 \pm 11.3(+3.6)$ & $61.0 \pm 7.9(+2.0)$ \\
\hline
\end{tabular}

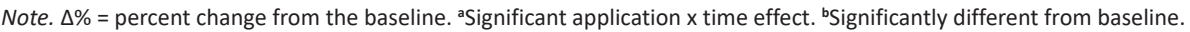

Table 2 Body temperature $\left({ }^{\circ} \mathrm{C}\right)$

\begin{tabular}{lccr}
\hline Group & $\begin{array}{c}\text { Baseline } \\
M \pm S D\end{array}$ & $\begin{array}{c}\text { After } 1^{\text {st }} \text { session } \\
M \pm S D(\Delta \%)\end{array}$ & $\begin{array}{c}\text { After } 2^{\text {nd }} \text { session } \\
M \pm S D(\Delta \%)\end{array}$ \\
\hline Cold water immersion & $36.3 \pm 0.4$ & $36.2 \pm 0.5(-0.3)$ & $36.6 \pm 0.5^{\mathrm{b}}(+0.8)$ \\
Passive recovery & $36.2 \pm 0.3$ & $37.0 \pm 0.3^{\mathrm{b}}(+0.8)$ & $37.0 \pm 0.3^{\mathrm{b}}(+1.1)$ \\
Active recovery & $36.2 \pm 0.3$ & $37.0 \pm 0.3^{\mathrm{b}}(+0.8)$ & $37.0 \pm 0.3^{\mathrm{b}}(+1.4)$ \\
\hline
\end{tabular}

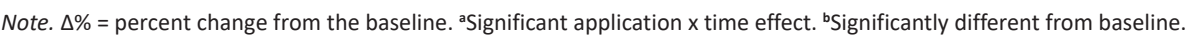

Table 3 Rating of perceived exertion

\begin{tabular}{lcc}
\hline Group & After $1^{\text {st }}$ session & After $2^{\text {nd }}$ session \\
$M \pm S D$ & $M \pm S D(\Delta \%)$ \\
\hline Cold water immersion & $15.6 \pm 1.3$ & $16.1 \pm 1.6(+2.9)$ \\
Passive recovery & $16.0 \pm 1.7$ & $16.3 \pm 1.6(+1.8)$ \\
Active recovery & $14.7 \pm 1.9$ & $16.2 \pm 1.7^{\mathrm{b}}(+10.5)$ \\
\hline
\end{tabular}

Note. $\Delta \%=$ percent change from the baseline. ${ }^{a}$ Significant application $\mathrm{x}$ time effect. ${ }^{\mathrm{b}}$ Significantly different from baseline. 
significant difference in the PP values after AR and PR. In another study, Malone et al. (2012) investigated performance parameters in trained triathletes after short-term recovery from supramaximal bouts of exercise and they found, no significant differences between active and passive recovery interventions on PP. Mussi (2018) examined the effect of CWI application on anaerobic performance and he found that there was no significant difference in PP. Considering the above study results, it can be said that different recovery methods do not have a significant effect on PP.

Mean power can be defined as the power produced during the $30 \mathrm{sec}$ test period (Özkan et al., 2010). The results of this study show that there is no significant difference in MP after all recovery methods. Similarly, Mussi (2018) compared the effects of AR and CWI on MP and he found that there was no significant difference in MP performance. On the other hand, Malone et al. (2012) investigated performance parameters in trained triathletes after short-term recovery from supramaximal bouts of exercise. Likewise, they found no significant differences between AR and PR interventions on MP. Contrary to the above study results, Schniepp et al. (2002) found that cold water application results in a significant decrease in MP. Frikha et al. (2016) examined the effect of warm-up duration on MP and they found that $15 \mathrm{~min}$ of active warming-up increased MP. Considering the current study and other study results, it can be said that AR, PR, and CWI applications do not have a significant effect on MP performance.

For the FI there was a significant application and time effects were found in CWI. CWI group had the lowest FI compared to AR and PR group. Similarly, Dixon et al. (2010) reported that when testing the power production of athletes, cold water exposure significantly decreased power output. At the same time Schniepp et al. (2002) found a significant decrease in short-term power output during CWI. On the contrary Malone et al. (2012) investigated performance parameters in trained triathletes after shortterm recovery from supramaximal bouts of exercise. No significant difference was found between active and passive recovery interventions for FI.

Fatigue index is defined as the percent reduction in power during WAnT (Özkan et al., 2010). A possible explanation for the decrease in power output during cold water application is that cooling of the muscles affects the nervous system (Montgomery \& Macdonald, 1990). Cool tissues decrease the rate of nerve transmission by reducing the production of acetylcholine at the neuromuscular junction (Abramson et al., 1966). The study of Herrera et al. (2010) supported this view. In their study, they compare the effects of the ice pack, ice massage, and cold water immersion on the conduction parameters of the sural (sensorial) and tibial motor nerves and they found that cold water immersion influences nerve conduction parameters.

In terms of BT, there was a time effect in CWI, PR, and AR groups. The highest increase was found in the AR group during the $2^{\text {nd }}$ session. Herrera et al. (2010) compared trhee different cold application methods (ice pack, ice massage, and cold water immersion) on BT and they found that all three methods reduced skin temperature. Moreover, Peiffer et al. (2009) investigated the effect of cold water immersion duration on body temperature and muscle function and they found a significantly greater rate of decrease in rectal temperature for all cold water immersion conditions. This is not in line with Mussi (2018) who investigated the effects of CWI and AR application on BT and found no significant difference between CWI and AR in temperature. Chaâri et al. (2015) study demonstrated that a 5-min post-warm-up rest interval did not generate a drop in core temperature and help to maintain an elevated state of preparedness, which has a direct impact on the subsequent high-intensity cycling performance. Immersion in water and cold application causes a decrease in body temperature. Therefore, a decrease in body internal temperature occurs.

A significant time effect was found in RPE. It was found that there was a $10.5 \%$ increase in the active recovery between $1^{\text {st }}$ and $2^{\text {nd }}$ session. Similarly, Scudese et al. (2016) reported that perceived effort data showed an important increase from the second set for active recovery. De Pauw et al. (2013) showed that CWI was significantly better than $\mathrm{AR}$ at improving RPE. Moreover, Rowsell et al. (2009) reported the perception of leg soreness and general fatigue was also lower in the cold water immersion than in the thermoneutral immersion group. In addition, all players in the cold water immersion condition reported that the cold water immersion recovery was beneficial for their recovery. On the contrary, Mussi (2018) compared active recovery and cold water immersion on the rating of perceived recovery and he found that there was no significant difference. These results suggest that cold water immersion might reduce the perceived exertion during consecutive matches in a few days.

\section{Conclusions}

The results indicate that during intermittent recovery, cold water immersion helped maintain performance and positively impacted countermovement jump and fatigue index, while the active recovery was positively affected countermovement jump performance and negatively affected the rating of perceived exertion. Thus our findings suggest that 10 min of cold water immersion and active recovery can be adopted in competitions when successive matches take place.

\section{Acknowledgments}

We would like to thank all the athletes who participated in this study.

\section{Conflict of interest}

The authors report no conflict of interest.

\section{References}

Abramson, D. I., Chu, L. S., Tuck, S., Lee, S. W., Richardson, G., \& Levin, M. (1966). Effect of tissue temperatures and blood flow on motor nerve conduction velocity. Journal of the American Medical Association, 198(10), 1082-1088. https:// doi.org/10.1001/jama.198.10.1082 
Ascensão, A., Leite, M., Rebelo, A. N., Magalhäes, S., \& Magalhäes, J. (2011). Effects of cold water immersion on the recovery of physical performance and muscle damage following a one-off soccer match. Journal of Sports Sciences, 29(3), 217-225. https://doi.org/10.1080/02640414.2010.526132

Belkadi, A. D. E. L., Mokhtar, M., Abdelkader, B., Mohamed, S., \& Othman, B. (2019). Effects of tow protocol cold water immersion on the post-match recovery and physical performance in youth handball players. International Journal of Sport Culture and Science, 7(2), 1-12. https://doi.org/10.14486/ intjscs.2019254980

Bielik, V. (2010). Effect of different recovery modalities on anaerobic power in off-road cyclists. Biology of Sport, 27(1), 59-63. https://doi. org/10.5604/20831862.907953

Borg, G. (1970). Physical training. 3. Perceived exertion in physical work. Lakar tidningen, 67(40), 4548-4557.

Calder, A. (2003). Recovery strategies for sports performance. USOC Olympic Coach E-Magazine, 15(3), 8-11.

Chaâri, N., Frikha, M., Mezghanni, N., Ayadi, J., Chaouachi, A., \& Souissi, N. (2015). Does post-warm-up rest interval affect the diurnal variation of 30-s Wingate cycle ergometry? Biological Rhythm Research, 46(6), 949-963. https:// doi.org/10.1080/09291016.2015.1073477

Cohen, J. (1988). Statistical power analysis for the behavioral sciences (2nd ed.) Routledge. https://doi.org/10.4324/9780203771587

De Pauw, K., Roelands, B., Marušič, U., Tellez, H. F., Knaepen, K., \& Meeusen, R. (2013). Brain mapping after prolonged cycling and during recovery in the heat. Journal of Applied Physiology, 115(9), 1324-1331. https://doi.org/10.1152/ japplphysiol.00633.2013

Dixon, P. G., Kraemer, W. J., Volek, J. S., Howard, R. L., Gomez, A. L., Comstock, B. A., \& Maresh, C. M. (2010). The impact of cold-water immersion on power production in the vertical jump and the benefits of a dynamic exercise warmup. Journal of Strength and Conditioning Research, 24(12), 3313-3317. https:// doi.org/10.1519/isc.0b013e3181f212e2

Doeven, S. H., Brink, M. S., Kosse, S. J., \& Lemmink, K. A. (2018). Post-match recovery of physical performance and biochemical markers in team ball sports: A systematic review. BMJ Open Sport \& Exercise Medicine, 4(1), Article e000264. https://doi.org/10.1136/bmisem-2017-000264

Dupuy, O., Douzi, W., Theurot, D., Bosquet, L., \& Dugué, B. (2018). An evidencebased approach for choosing post-exercise recovery techniques to reduce markers of muscle damage, soreness, fatigue, and inflammation: A systematic review with meta-analysis. Frontiers in Physiology, 9, Article 403. https://doi. org/10.3389/fphys.2018.00403

Frikha, M., Chaâri, N., Mezghanni, N., \& Souissi, N. (2016). Influence of warmup duration and recovery interval prior to exercise on anaerobic performance. Biology of Sport, 33(4), 361-366. https://doi.org/10.5604/20831862.1221830

Halson, S. L. (2013). Recovery techniques for athletes. Sports Science Exchange, 26(120), 1-6. https://www.gssiweb.org/sports-science-exchange/article/ sse-120-recovery-techniques-for-athletes

Hammami, N., Hattabi, S., Salhi, A., Rezgui, T., Oueslati, M., \& Bouassida, A. (2018). Combat sport injuries profile: A review. Science \& Sports, 33(2), 73-79. https://doi.org/10.1016/j.scispo.2017.04.014

Hausswirth, C., \& Le Meur, Y. (2011). Physiological and nutritional aspects of post-exercise recovery. Sports Medicine, 41(10), 861-882. https://doi. org/10.2165/11593180-000000000-00000

Herrera, E., Sandoval, M. C., Camargo, D. M., \& Salvini, T. F. (2010). Motor and sensory nerve conduction are affected differently by ice pack, ice massage, and cold water immersion. Physical Therapy, 90(4), 581-591. https://doi.org/10.2522/ pti.20090131

Higgins, T. R., Greene, D. A., \& Baker, M. K. (2017). Effects of cold water immersion and contrast water therapy for recovery from team sport: A systematic review and meta-analysis. Journal of Strength and Conditioning Research, 31(5), 1443-1460. https://doi.org/10.1519/isc.0000000000001559

Ihsan, M., Watson, G., \& Abbiss, C. R. (2016). What are the physiological mechanisms for post-exercise cold water immersion in the recovery from prolonged endurance and intermittent exercise? Sports Medicine, 46(8), 1095-1109. https://doi.org/10.1007/s40279-016-0483-3

Inbar, O., Bar-Or, O., \& Skinner, J. S. (1996). The Wingate anaerobic test. Human Kinetics.

King, M., \& Duffield, R. (2009). The effects of recovery interventions on consecutive days of intermittent sprint exercise. Journal of Strength and Conditioning Research, 23(6), 1795-1802. https://doi.org/10.1519/isc.0b013e3181b3f81f

Lattier, G., Millet, G. Y., Martin, A., \& Martin, V. (2004). Fatigue and recovery after high-intensity exercise. Part II: Recovery interventions. International Journal of Sports Medicine, 25(7), 509-515. https://doi.org/10.1055/s-2004-820946

Malone, J. K., Coughlan, G. F., Crowe, L., Gissane, G. C., \& Caulfield, B, (2012) The physiological effects of low-intensity neuromuscular electrical stimulation
(NMES) on short-term recovery from supra-maximal exercise bouts in male triathletes. European Journal of Applied Physiology, 112(7), 2421-2432. https:// doi.org/10.1007/s00421-011-2212-9

Medina-Porqueres, L. Moreno-Morales, N., Palenque-Lobato, F. J., Sanz-DeDiego, S., \& Baron-Lopez, F. J. (2016). Immediate effects of cold water immersion on vertical jump and perceived exertion in women. Annals of Yoga \& Physical Therapy, 1(2), Article 1009. https://austinpublishinggroup.com/voga-physical-therapy/fulltext/aypt-v1-id1009.php

Monedero, J., \& Donne, B. (2000). Effect of recovery interventions on lactate removal and subsequent performance. International Journal of Sports Medicine, 21(8), 593-597. https://doi.org/10.1055/s-2000-8488

Montgomery, J. C., \& Macdonald, J. A. (1990). Effects of temperature on nervous system: Implications for behavioral performance. American Journal of Physiology-Regulatory, Integrative and Comparative Physiology, 259(2), R191-R196. https://doi.org/10.1152/ajpregu.1990.259.2.r191

Mooventhan, A., \& Nivethitha, L. (2014). Scientific evidence-based effects of hydrotherapy on various systems of the body. North American Journal of Medical Sciences, 6(5), 199-209. https://doi.org/10.4103/1947-2714.132935

Mussi, E., Jr. (2018). Active recovery vs. cold water immersion with neoprene for exercise recovery [Master thesis, Ithaca College]. Ithaca College Theses. https:// digitalcommons.ithaca.edu/ic theses/390

Ouergui, I., Hammouda, O., Chtourou, H., Gmada, N., \& Franchini, E. (2014) Effects of recovery type after a kickboxing match on blood lactate and performance in anaerobic tests. Asian Journal of Sports Medicine, 5(2), 99-107. https://sites.kowsarpub.com/asjsm/articles/76676.html

Özkan, A., Köklü, Y., \& Ersöz, G. (2010). Wingate anaerobic power test. Journal of Human Sciences, 7(1), 207-224. https://www.j-humansciences.com/ojs/index.php/ IJHS/article/view/942

Peiffer, J. J., Abbiss, C. R., Watson, G., Nosaka, K., \& Laursen, P. B. (2009). Effect of cold-water immersion duration on body temperature and muscle function. Journal of Sports Sciences, 27(10), 987-993. https://doi. org/10.1080/02640410903207424

Reilly, T., \& Ekblom, B. (2005). The use of recovery methods post-exercise. Journal of Sports Sciences, 23(6), 619-627. https://doi.org/10.1080/02640410400021302 Rey, E., Lago-Peñas, C., Casáis, L., \& Lago-Ballesteros, J. (2012). The effect of immediate post-training active and passive recovery interventions on anaerobic performance and lower limb flexibility in professional soccer players. Journal of Human Kinetics, 31, 121-129. http://johk.pl/files/113ray.pdf

Ronglan, L. T., Raastad, T., \& Borgesen, A. (2006). Neuromuscular fatigue and recovery in elite female handball players. Scandinavian Journal of Medicine \& Science in Sports, 16(4), 267-273. https://doi.org/10.1111/j.1600-0838.2005.00474.x

Rowsell, G. J., Coutts, A. J., Reaburn, P., \& Hill-Haas, S. (2009). Effects of coldwater immersion on physical performance between successive matches in high-performance junior male soccer players. Journal of Sports Sciences, 27(6), 565-573. https://doi.org/10.1080/02640410802603855

Sanders, J. (1996). Effect of contrast-temperature immersion on recovery from short-duration intense exercise [Unpublished bachelor thesis]. University of Canberra.

Sayers, S. P., Harackiewicz, D. V., Harman, E. A., Frykman, P. N., \& Rosenstein, M. T. (1999). Cross-validation of three jump power equations. Medicine \& Science in Sports \& Exercise, 31(4), 572-577. https://doi. org/10.1097/00005768-199904000-00013

Schniepp, J., Campbell, T. S., Powell, K. L., \& Pincivero, D. M. (2002). The effects of cold-water immersion on power output and heart rate in elite cyclists. Journal of Strength and Conditioning Research, 16(4), 561-566. https://doi. org/10.1519/00124278-200211000-00012

Scudese, E., Senna, G., Meza, E. A., Zarlotti, C., de Oliveira, A. B., \& Dantas, E. H. M. (2016). Effect of different recovery methods in strength training on performance and perceived exertion. Revista Andaluza de Medicina del Deporte. Advance online publication. https://doi.org/10.1016/j.ramd.2015.12.003

Sharma, L., Hussain, M. E., \& Verma, S. (2017). Effect of recovery modalities on blood lactate clearance. Saudi Journal of Sports Medicine, 17(2), 65-69. https:// doi.org/10.4103/1319-6308.207577

Tokmakidis, S. P., Toubekis, A. G., \& Smilios, I. (2011). Active versus passive recovery: Metabolic limitations and performance outcome. In M. A. Powell (Ed.), Physical fitness training, effects and maintaining (pp. 1-43). Nova Science Publishers.

Wiewelhove, T., Schneider, C., Schmidt, A., Döweling, A., Meyer, T., Kellmann, M., \& Ferrauti, A. (2018). Active recovery after high-intensity interval-training does not attenuate training adaptation. Frontiers in Physiology, 9, Article 415. https://doi.org/10.3389/fphys.2018.00415

Wilcock, I. (2005). The effect of water immersion, active recovery and passive recovery on repeated bouts of explosive exercise and blood plasma fraction [Unpublished doctoral dissertation]. Auckland University of Technology. 